\title{
Fungal Endophytes of Tahiti Lime (Citrus citrus $\times$ latifolia) and Their Potential for Control of Colletotrichum acutatum J. H. Simmonds Causing Anthracnose
}

\section{OPEN ACCESS \\ Edited by: \\ Adeline Su Yien Ting}

Monash University Malaysia, Malaysia

Reviewed by:

Altemir J. Mossi,

Universidade Federal da Fronteira Sul,

Brazil

Rafael Resende Maldonado,

State University of Campinas, Brazil

*Correspondence: Beatriz E. Guerra-Sierra

bguerra@udes.edu.co

tORCID:

Jaider Muñoz-Guerrero orcid.org/0000-0002-6931-1486

Beatriz E. Guerra-Sierra orcid.org/0000-0002-1830-1974

Javier C. Alvarez orcid.org/0000-0001-9009-823X

Specialty section:

This article was submitted to Bioprocess Engineering,

a section of the journal Frontiers in Bioengineering and Biotechnology

Received: 07 January 2021 Accepted: 15 March 2021 Published: 01 April 2021

Citation:

Muñoz-Guerrero J,

Guerra-Sierra BE and Alvarez JC (2021) Fungal Endophytes of Tahiti Lime (Citrus citrus $\times$ latifolia) and Their Potential for Control of Colletotrichum acutatum J. H. Simmonds Causing

Anthracnose.

Front. Bioeng. Biotechnol. 9:650351. doi: 10.3389/fbioe.2021.650351

\section{Jaider Muñoz-Guerrero ${ }^{1 \dagger}$, Beatriz E. Guerra-Sierra ${ }^{1 * \dagger}$ and Javier C. Alvarez ${ }^{2 \dagger}$}

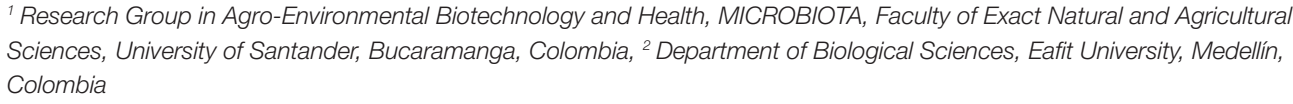

'Research Group in Agro-Environmental Biotechnology and Health, MICROBIOTA, Faculty of Exact Natural and Agricultural Sciences, University of Santander, Bucaramanga, Colombia, ${ }^{2}$ Department of Biological Sciences, Eafit University, Medellin, Colombia

Colletotrichum acutatum is one of the causal agents of anthracnose in several crops, and of post-flowering fruit drop (PFD) in citrus and key lime anthracnose (KLA). The pathogen normally attacks flowers, causing lesions only in open flowers. Under very favorable conditions, however, it can also affect flower buds and small fruits, causing complete rotting of the fruit and a premature fall, resulting in major economic crop losses. We isolated endophytic fungi from Tahiti lime to evaluate its diversity, verify its antagonistic capacity against the phytopathogen Colletotrichum acutatum C-100 in dual tests, and evaluate the ability of various endophytic agents to control flowers with induced anthracnose. 138 fungal isolates were obtained from 486 fragments of branches, leaves, and fruit; from which 15 species were identified morphologically. A higher isolation frequency was found in branches and leaves, with a normal level of diversity compared to other citrus species. Of the 15 morphospecies, 5 were trialed against $C$. acutatum in antagonism tests, resulting in a finding of positive inhibition. 2 endophytic fungi from the antagonism tests demonstrated high inhibition of the phytopathogen, and were thus used in in vivo tests with Tahiti lime flowers, applied in a spore solution. Spore solutions of two molecularly identified species, Xylaria adscendens, and Trichoderma atroviride, reduced the lesions caused by the phytopathogen in these in vivo tests. The finding that these endophytes react antagonistically against $C$. acutatum may make them good candidates for further biological control research in an agroindustry that requires environmental sustainability.

Keywords: mycobiota, biocontrol, citrus, phytopathogens, antagonism

\section{INTRODUCTION}

The appearance of diseases in citrus crops reduces the quantity that can be produced and sold, even more so when the products are to be exported (Tennant et al., 2009; Donkersley et al., 2018). Many citrus diseases are caused by phytopathogens, which colonize various plant tissues and affect organs such as flowers and fruits both before and after harvesting (Bazioli et al., 2019). 
Citrus varieties found in tropical and subtropical zones around the world are frequently infected by phytopathogenic fungi species which cause diseases such as anthracnose (Silva-Junior et al., 2014; Rhaiem and Taylor, 2016), a condition linked to Colletotrichum (Cannon et al., 2012; Ben Hadj Daoud et al., 2019; Mogollón et al., 2021).

Anthracnose is a serious disease in citrus, manifesting itself in symptoms such as necrosis of leaves and flowers, and the premature drop of fruit after flowering; the latter being especially harmful to the crop (Silva-Junior et al., 2014; Frare et al., 2016; Wang et al., 2021). Colletotrichum gloeosporioides and Colletotrichum acutatum are two of the species most responsible for anthracnose in citrus (Barquero et al., 2013; Ramos et al., 2016; Ben Hadj Daoud et al., 2019), including the acid lime and Tahiti lime (Citrus citrus $\times$ latifolia). Of the two varieties, Tahiti limes are more commercially common, as they are generally larger and contain more juice than key limes (Evans et al., 2014). Anthracnose results in negative phytosanitary effects and crop reductions for this important cultivar (Lima et al., 2011; Mogollón et al., 2021; Wang et al., 2021).

One possible control methodology for diseases such as anthracnose is the use of conventional fungicides (Palou et al., 2008; Bazioli et al., 2019). However, although these pesticides do help control various species of phytopathogens, their indiscriminate use also results in undesirable impacts upon the environment (Yoon et al., 2013; Price et al., 2015). Furthermore, intensive use of these agrochemicals, including in citrus crops, can lead to the generation of resistance mechanisms among phytopathogenic fungal populations (Price et al., 2015; Forcelini and Peres, 2018). Thus, biological control strategies are increasingly attractive for this type of agriculture (Pekas, 2011; Wang et al., 2018, 2020; Rojas et al., 2020), more so in the current era of sustainable agriculture, which emphasizes the reduction or elimination of fertilizers and other agrochemicals (Arora, 2018). Biological control presents a viable and environmentally friendly solution (Droby et al., 2009; De Silva et al., 2019).

Among biological control options, endophytic fungi have become a resource of interest to the agricultural world to control disease (Latz et al., 2018; De Silva et al., 2019; Ortega et al., 2020) and improve crop yields (Abo, 2019; Segaran and Sathiavelu, 2019; Rojas et al., 2020). The symbiotic interactions of these fungi, and their ability to coexist safely with the tissues of the host plant make possible the production of bioactive compounds for the control of pests and pathogens that attack plants (Selim, 2012; Kusari et al., 2013; Caruso et al., 2020). In crops, there is a pressing need to find new solutions, making the exploration of endophytic mycobiota in species such as Tahiti lime important. In the present paper, we to identify endophytic fungi in Tahiti lime (Citrus citrus $\times$ latifoliain order to evaluate their diversity and antagonistic capacity both in vitro and in vivo against a strain of phytopathogenic fungus Colletotrichum acutatum C-100, previously isolated from Tahiti lime flowers with anthracnose.

\section{MATERIALS AND METHODS}

\section{Sample Collection}

Healthy Tahiti lime (Citrus citrus $\times$ latifolia) plant tissues (without visual disease) such as leaves, stems, and fruits were obtained from local farms, located in the municipality of Girón, Santander, Colombia at coordinates: $7^{\circ} 1^{\prime} 31.59^{\prime \prime} \mathrm{N} ; 73^{\circ} 9^{\prime}$ $18.77^{\prime \prime} \mathrm{W}$ and $7^{\circ} 1^{\prime} 31.78^{\prime \prime} \mathrm{N} ; 73^{\circ} 9^{\prime} 32.62^{\prime \prime} \mathrm{W}$. The samples were transported in a cold chain and processed in the agroenvironmental biotechnology laboratory (LIIBAAM_UDES) to isolate endophytic fungi within $6 \mathrm{~h}$ of collection. This same sampling procedure was carried out in six trips to the field.

\section{Endophyte Isolates}

Given that each sample consisted of a different mix of leaves, fruit, and fragments of branches, the samples were initially washed in distilled water for $10 \mathrm{~min}$, after which small segments of approximately $0.7 \mathrm{~cm}$ were cut. Thereafter, the samples were placed in separate Petri dishes for surface disinfection in a solution of alcohol (70\%) for 2 min, sodium hypochlorite (2.5\%) for $2 \mathrm{~min}$, and then two separate washes with distilled water for 2 min each, using a protocol adapted from Kjer et al. (2010). Once the tissue fragments were disinfected, they were seeded in Petri dishes with Potato Dextrose Agar (PDA) supplemented with chloramphenicol and incubated for 10 days at $26^{\circ} \mathrm{C}$. Daily inspection was carried out to select the endophytic fungi that appeared. An equal number of non-disinfected vegetal segments were prepared as a control for the disinfection process, and seeded in the mycological medium to allow for fungal growth. Fractions of fungal mycelium emerging from the plant tissues were extracted aseptically in a laminar flow cabinet to avoid contact with adjacent samples, and these fungal segments were seeded into individual Petri dishes with PDA medium. This process was carried out in triplicate to obtain pure colonies for subsequent characterization and identification.

\section{Colonization Frequency and Relative Isolation Frequency}

The isolation frequency rate (IR) was defined as the number of endophytic fungi isolated divided by the total number of incubated fragments and expressed as a percentage. The relative frequency of isolation (FR) was calculated as the number of isolates of a given morphospecies divided by the total number of isolates, expressed as a percentage. This information was analyzed by a one-way ANOVA with a Tukey test to identify any differences between tissue types (leaves, branches and fruits).

\section{Characterization of Fungal Endophytes and Analysis of Diversity}

Endophytic fungi were initially identified by morphospecies, based on the morphological characteristics of the colonies grown in PDA medium (colony appearance, diffusible pigments, front and back color, borders, texture, and growth rate) (Tibpromma et al., 2018; Estrada and Ramírez, 2019; da Costa Silveira et al., 2020). To determine these microscopic characteristics, preparations of the isolated endophytes were made in new PDA 
media, using microcultures and encouraging their sporulation. The specimens were then placed on slides with lactic acid and ethanol solution, allowing for the visualization of the mycelia using an optical microscope (Nikon eclipse-NI-U). The morphological characteristics of the isolates (hyphae and spores) were compared with previous descriptions drawn from the literature, bibliographic resources, and taxonomic keys (Barnett and Hunter, 1998; Estrada and Ramírez, 2019; da Costa Silveira et al., 2020). Isolates that did not sporulate were placed in darkness at room temperature for up to 20 days to stimulate sporulation. Those isolates that still did not produce spores were treated as sterile mycelia.

\section{Diversity Analysis}

The diversity of endophytic morphotypes was measured using diversity indices whose parameters are the richness and relative abundance of species, and which evaluate the contribution of individuals to the community (Chao et al., 2005). Specifically, the study used the Shannon-Wiener $\left(\mathrm{H}^{\prime}\right)$ and Simpson (D) indices. The former measures the information content per individual in samples obtained at random from a "large" community in which the total number of species $(S)$ is known and which are sampled at random. This measurement can take values between 0 and 5 and is strongly influenced by the most abundant species (Jin et al., 2013). It is based on the following formula:

$$
H^{\prime}=-\Sigma(P i \times \ln P i) \text {. }
$$

The latter, Simpson's diversity index, measures the probability of finding two individuals of the same species in two successive random draws without replacement, by the following formula: $(1-\mathrm{D})$ (formula: $1-[\mathrm{D}=\Sigma(\mathrm{ni} / \mathrm{n}) 2])$, where ni, is the number of distinct species (i) and ( $n$ ) is the abundance of each species in the community. The species evenness (E), which assesses the contribution of the individuals to the community, was also calculated using the following formula: $\mathrm{E}=\mathrm{H} / \mathrm{ln} S$, where $\mathrm{S}=$ the number of species in the sample. The above calculations were all made using PAST 4 software and Estimates (Colwell, 2004).

\section{Tests for Antagonism: Endophytic Fungi vs. Colletotrichum acutatum}

The fungal morphospecies obtained from the isolates were seeded in a medium of PDA / water agar (at a 1:3 ratio), for stressful growth. The fungi which grew in the first 5 days and demonstrated the highest growth radii were selected for the antagonism tests with the reference phytopathogenic fungi Colletotrichum acutatum C-100 that was isolated earlier from Tahiti lime flowers with anthracnose (Martinez et al., 2009). Mycelium discs of $5 \mathrm{~mm}$ diameter with both the endophytes and the phytopathogenic fungus were planted equidistantly in Petri dishes with PDA + chloramphenicol medium spaced $10 \mathrm{~mm}$ from the edge of the dish, and were incubated at $26^{\circ} \mathrm{C}$. All of the endophyte-phytopathogen antagonism tests were performed in triplicate. They were observed daily, and the antagonistic capability of each fungus was determined, expressed as a percentage of the radial inhibition of the pathogen's growth (PIRG-P) and the endophyte's (PIRG-E), using the following formula for the calculation (López et al., 2017):

$$
\mathrm{PIRG}-\mathrm{P} \text { or }-\mathrm{E}(\%)=(\mathrm{R} 1-\mathrm{R} 2) / \mathrm{R} 1] \times 100
$$

Where R1 indicates the radial growth of the phytopathogen or the endophyte colony in control plates and R2 indicates the radial growth of the phytopathogen or the endophyte colony (in the direction of the other fungus) during the antagonism trials. To determine the type of interaction between the endophyte and the phytopathogen, the following scale was used with 5 types of interactions, adapted from López et al. (2017): (1): The two opposing fungi demonstrate similar growth and overlap; (2): the endophytic fungus outgrows the pathogenic one; (3): the phytopathogenic fungus outgrows the endophytic one; (4 and 5): mutual inhibition of the two colonies at a short distance $(<2 \mathrm{~mm})$ or larger distance $(>2 \mathrm{~mm})$, respectively. An ANOVA analysis with a Bonferroni test was applied a posteriori to compare the inhibition of the growth between the opposing fungi and verify which endophytic fungi had the greatest inhibitory impact on the phytopathogen.

\section{In vivo Tests on Flowers and Severity Estimation}

Of the in vitro antagonism tests, the two morphospecies of endophytic fungi (EFTL-10 and EFTL-13) with the best inhibition results against C. acutatum C-100 were selected for severity tests on the flowers of Tahiti lime. Spore solutions were prepared from these two fungi with which the petals of the Tahiti lime flowers were inoculated. Mycelium sections of the two fungi were grown in flasks of liquid medium. The flasks were incubated in laboratory conditions using a rotating agitator at $140 \mathrm{rpm}$ and a temperature of $25^{\circ} \mathrm{C}$ for 1 week to allow for the fungi to sporulate and disperse spores through the medium. From this stock solution, 5 serial dilutions were prepared to determine which was best for the inoculation. The spore density was measured in a Neubauer chamber, and the suspension was standardized using a final concentration of $1 \times 10^{3}$ spores $/ \mathrm{mL}$.

The treatments were carried out in a greenhouse at a temperature of $24 \pm 2{ }^{\circ} \mathrm{C}$ and relative humidity of $80 \%$, and using a completely randomized experimental design in triplicate. The Tahiti lime flowers used were in fresh anthesis (flower opening). Each set of flowers was washed with distilled water and $2.0 \%$ sodium hypochlorite for $1 \mathrm{~min}$. 5 flowers were treated in the following manner:

T1: flowers inoculated with a solution of phytopathogenic spores of Colletotrichum acutatum;

T2: flowers inoculated with a solution of phytopathogenic spores + endophytic spore solution 1 at $12 \mathrm{~h}$; T3: flowers inoculated with a solution of phytopathogenic spores + endophytic spore solution 2 at 12 h; T4: 5 flowers inoculated with distilled water as a control. All of the treatments were inspected at 12,48 , and $72 \mathrm{~h}$ for the final measurement of petal lesions, according to a protocol adapted from Goulin et al. (2019).

To calculate the lesion percentage (necrosis) on the Tahiti lime flowers, the petals were initially measured lengthwise using a vernier caliper, after which a photograph was taken with a conventional digital camera in jpg format. The photos were 
scaled in AutoCAD ${ }^{\circledR}$ V. 19 software based on the actual petal area measurements. With the image scaled, the total area of the flower was delimited, and the affected area (that with lesions) was determined and expressed as a percentage, using the following scale of severity (adapted from Lakshmi et al., 2011).

\begin{tabular}{lc}
\hline Flower area affected & Level \\
\hline None & 0 \\
Up to $5 \%$ & 1 \\
$6-10 \%$ & 2 \\
$11-20 \%$ & 3 \\
$21-50 \%$ & 4 \\
More than 50\% & 5 \\
\hline
\end{tabular}

With the numeric values above, apercent severity index (PSI) was calculated for the flowers, using the following formula:

Percent Severity Index $=\frac{\text { Sum of numerical ratings } \times 100}{* \text { Number of units } \times \text { Maximum grade }}$

* flower

To arrive at a general result for the percentage of severity in the average lesions of the flowers, the following classification was used:

\begin{tabular}{lcc}
\hline Group & Percent severity index & Symptomatology \\
\hline Highly virulent & $>40$ & Large confluent necrotic areas \\
Moderately virulent & $>30-40$ & Numerous small necrotic spots \\
Less virulent & $<30$ & Few necrotic spots \\
\hline
\end{tabular}

Shivakumar et al. (2016).

\section{Isolation of Fungal DNA and Molecular Identification}

The endophytic fungal morphospecies (EFTL-10 and EFTL13) used in the Tahiti lime flower severity tests were seeded in new PDA media to obtain pure colonies and extract biomass from mycelia after 8 days of growth. DNA was extracted using DNeasy Powerlyzer Power Soil Kit (Qiagen) according to t22he supplier's extraction protocol. The evaluation of the purity and quantification of the DNA extracted from the fungal samples was carried out by spectrophotometry using Nanodrop 2000c (Thermo Scientific), calculating the concentration in $\mathrm{ng} / \mu \mathrm{L}$, with dilutions adjusted for absorbance readings at $260 \mathrm{~nm}$ and the yield was calculated as the amount of DNA obtained (ng) over the weight of mycelium used for extraction $(\mu \mathrm{g})$. The extractions were carried out in triplicate.

Markers ITS and TEF were amplified and used for taxonomic purposes. ITS region was amplified using the fungal universal primers ITS1 and ITS 4; ITS1: 5' TCCGTAGGTGAACCTGCGG 3'-ITS4: 5' TCCTCCGCTTATTGATATGC 3'; TEF region was amplified using the fungal universal primers TEF_983F:
5' GCYCCYGGHCAYCGTGAYTTYAT3' TEF_2218R:5'AT GACACCRACRGCRACRGTYTG 3', and then capillary sequenced. ITS and TEF sequences were aligned using the MAFFT package and the alignment was imported into MEGA v7. The sequence data generated were compared against the GenBank database through BLAST ${ }^{1}$ to determine their most probable closely related taxa. Phylogenetic analysis using ITS datasets was conducted for the taxonomic study of the EFTL-10 and EFTL-13 isolates. A maximum-likelihood phylogenetic tree was performed using IQtree software. We used the TIM2e+I+G4 model, Ultrafast Bootstrap (Hoang et al., 2018) with 1,000 replicates.

\section{RESULTS}

\section{Isolation, Characterization, and Diversity of Endophytic Fungi}

Fifteen morphospecies of endophytic fungi were isolated from the tissues of the Tahiti lime and identified using the code EFTL(Endophytic Fungi Tahiti Lime), as illustrated in Figure 1. The endophytic fungi were identified using traditional morphological identification methods. The morphological characteristics of these fungi indicate that they belong to the Ascomycetes. Only two were classified as sterile mycelium. Fungi represented in these findings include the genera: Phoma sp., Fusarium sp., Curvularia sp., Colletotrichum sp., Diaporthe sp., Verticillum sp., Xylaria sp., Nigrospora sp., Trichoderma sp., Alternaria sp., Phyllosticta sp., Chaetomium sp., and Micelia sterilia.

From a total of 486 fragments of branches, leaves, and fruit seeded in PDA media after each of the 6 sampling trips carried out, 138 fungal isolates were obtained. Table 1 indicates the morphospecies identified and the number of isolates, with the relative isolation frequency for each type of vegetal tissue. It can be observed that these endophytic isolates from branches, leaves, and fruit do not always exhibit the same isolation frequency. The maximum isolation frequency was observed in leaves (41.30\%), followed by branches $(39.86 \%)$, and fruit $(18.84 \%)$. An ANOVA test $(p<0.05)$ indicated that there are significant differences in the isolation frequencies between tissues, as is especially evident in the much lower frequency noted in fruit compared to branches and leaves.

The morphospecies isolated with the highest frequency from Tahiti limes were: EFTL-01; EFTL-03; EFTL-04; EFTL-06; EFTL08; EFTL-09; EFTL-11; and EFTL-12. Nevertheless, in all of the 6 samplings undertaken, the isolates from fruit exhibited the lowest frequency (Table 1).

The diversity of endophytic fungi was observed at the level of their richness (number of taxa $=S$ ) and abundance (number of isolates or individuals). It was noted that although richness of fungal morphospecies was similar for both branches and leaves, it was lower in fruit. The diversity of fungi found (Table 2), using Simpson's index, was very similar between the branches (0.92), leaves $(0.91)$, and fruit $(0.90)$. This is to say that a very similar distribution exists between the species sampled according

${ }^{1}$ http://blast.ncbi.nlm.nih.gov/ 


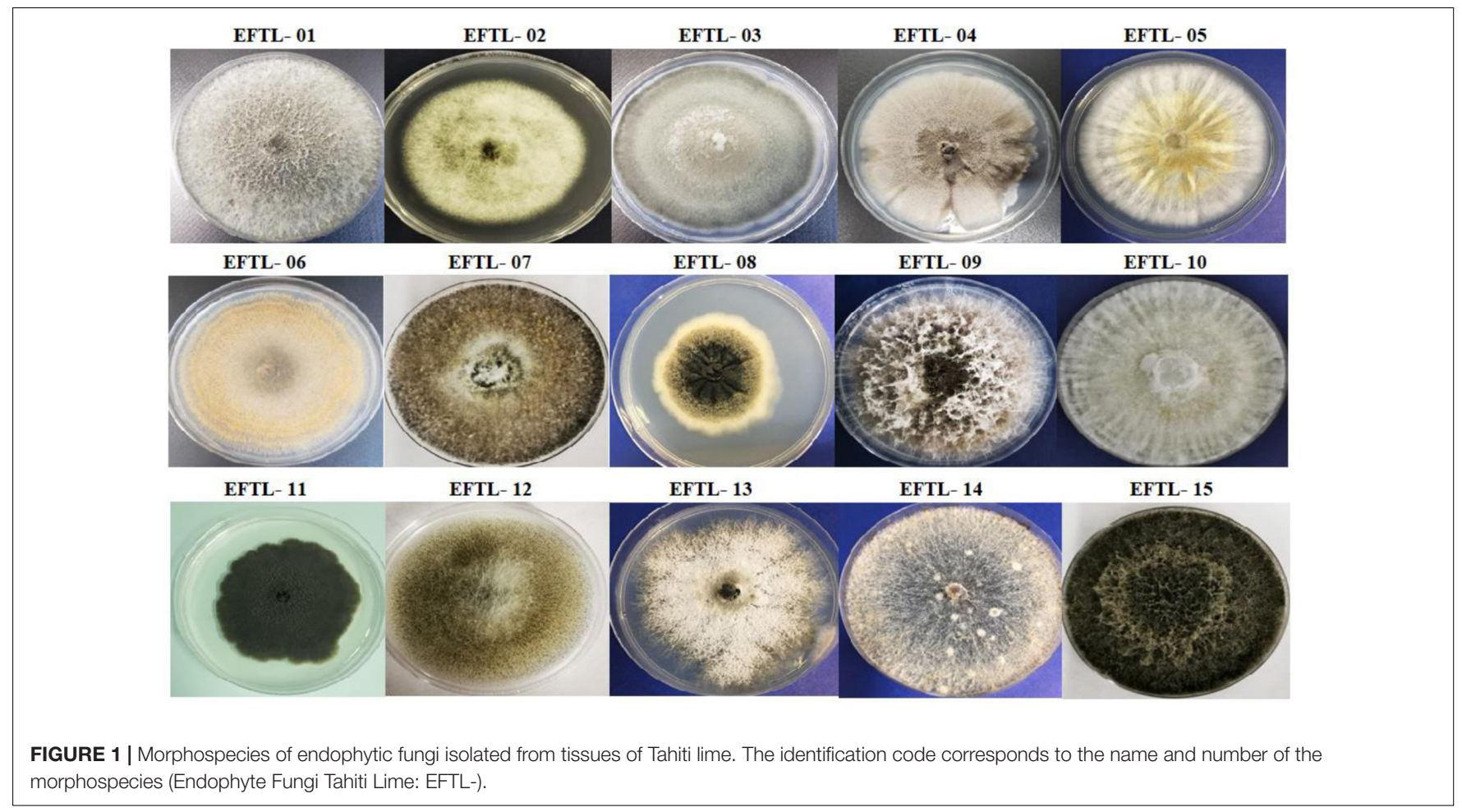

to the type of tissue. The Shannon-Wiener diversity index (with reference values from 0 to 5 ), indicates that there is a normal level of diversity in this fungal community (branches: 2.56; leaves: 2.52; fruit: 2.35) (Table 2). With respect to this indicator, the tissues were fairly equal, except for fruit, which was somewhat lower.

TABLE 1 | Number and relative frequencies of fungal isolates by colonized tissues of Tahiti lime.

\begin{tabular}{lcccc}
\hline \multirow{2}{*}{ Morphospecies } & Number of isolations & \multicolumn{3}{c}{ Relative frequency percentages } \\
\cline { 3 - 5 } & & 4.35 & 5.07 & 0.00 \\
& 13 & 1.45 & 0.72 & 1.45 \\
\hline EFTL-01 & 5 & 3.62 & 2.90 & 1.45 \\
EFTL-02 & 11 & 3.62 & 5.07 & 0.00 \\
EFTL-03 & 12 & 1.45 & 0.72 & 2.17 \\
EFTL-04 & 6 & 4.35 & 2.90 & 0.72 \\
EFTL-05 & 11 & 2.17 & 2.17 & 1.45 \\
EFTL-06 & 8 & 4.35 & 3.62 & 2.17 \\
EFTL-07 & 14 & 2.90 & 1.45 & 2.90 \\
EFTL-08 & 10 & 1.45 & 2.17 & 0.00 \\
EFTL-09 & 5 & 2.17 & 3.62 & 1.45 \\
EFTL-10 & 10 & 1.45 & 4.35 & 1.45 \\
EFTL-11 & 10 & 2.17 & 2.90 & 1.45 \\
EFTL-12 & 9 & 1.45 & 3.62 & 0.00 \\
EFTL-13 & 7 & 2.90 & 0.00 & 2.17 \\
EFTL-14 & 7 & 39.86 & 41.30 & 18.84 \\
\hline EFTL-15 & 138 & &
\end{tabular}

ANOVA: $F=5.064 ;(P=0.01)$.

*Morphospecies selected for antagonism tests.

\section{Antagonism Tests Against Phytopathogenic Fungi}

The 15 resulting fungal morphospecies were subjected to stressful growth with low nutrient conditions in a PDA medium for 8 days (before the antagonism tests). Only the fastest-growing after 5 days (EFTL-03, EFTL-04, EFTL-10, EFTL-12, and EFTL-13) (*Table 1) were selected to trial against the phytopathogen fungus Colletotrichum acutatum C-100.

During the first 7 days of dual growth, it was observed that the average radial growth inhibition percentages of the endophytic fungi were less than those of the phytopathogenic fungi (Table 3); that is, the endophytic fungi limited the growth of the phytopathogens in the culture medium, under the same temperature and nutrient conditions. Figure 2 illustrates the comparison in the dual tests (endophyte-phytopathogen) of the 5 endophytic fungi tested (EFTL-03, EFTL-04, EFTL-10, EFTL-12, and EFTL-13). Although they grew for the same experimental time, pairs $\mathbf{b}$ and $\mathbf{c}$ had higher values for their

TABLE 2 | Diversity indices of endophytic fungi from tissues sampled.

\begin{tabular}{lccc}
\hline & \multicolumn{3}{c}{ Tissue type } \\
\cline { 2 - 4 } Indicators & Branches & Leaves & Fruit \\
\hline Individuals (isolates) & 49 & 57 & 26 \\
Speciesrichness & 14 & 14 & 11 \\
Shannon- Wiener diversity & 2.56 & 2.52 & 2.35 \\
Simpson diversity & 0.92 & 0.91 & 0.90 \\
Speciesevenness & 0.92 & 0.89 & 0.95
\end{tabular}


TABLE 3 | Percent of radial growth inhibition of endophytic and phytopathogenic fungi (Colletotrichum acutatum C-100).

\begin{tabular}{lllrc}
\hline Dual trial & $\begin{array}{l}\text { Fungal } \\
\text { morphospecies }\end{array}$ & $\begin{array}{l}\text { Type of } \\
\text { interaction }\end{array}$ & (PIRG-E-\%) & (PIRG-P-\%) \\
\hline A & EFTL-03 & 5 & $3.54 \pm 1.6$ & $5.26 \pm 1.3$ \\
B & EFTL-04 & 5 & $19.80 \pm 1.4$ & $21.47 \pm 1.1$ \\
C & EFTL-10 & $2++$ & $27.00 \pm 2.3$ & $29.09 \pm 1.6$ \\
D & EFTL-12 & 5 & $18.06 \pm 0.2$ & $6.38 \pm 1.3$ \\
E & EFTL-13 & $2+$ & $10.10 \pm 0.3$ & $12.90 \pm 0.1$ \\
& & & &
\end{tabular}

Means of percentage of growth inhibition $\pm S D$.

percentage of inhibition for each fungus; nevertheless, there are significant differences between these pairs (ANOVA/Bonferroni test; $F=6.738 ; \quad P=0.0013)$, with the phytopathogen largely inhibited.

When the trials were completed after 10 days, the fungi maintained a similar mycelial distribution in three of the pairs $(A, B, D)$ as is shown in Figure 3. Here, it can be seen that both did not continue growing, but rather that they exhibited a Type5 interaction, where the opposing fungi demonstrated similar growth but maintained a distance of $>2 \mathrm{~mm}$ between them (black arrows in Figure 3). The c and e pairs exhibited a Type2 interaction, where the mycelium of the endophytic fungus outgrew that of the phytopathogenic. This is seen to be most true in pair $\mathbf{c}(2++)$, and slightly in pair e $(2+)$ (Figure 3). Due to their performance, these two fungi were selected for the following in vivo tests.

\section{Severity Tests on Tahiti Lime Flowers}

In each of the tests to evaluate the severity of C. acutatum C-100 on Tahiti lime flowers previously inoculated with the phytopathogen and then counter-inoculated with a $10^{3}$ spore $/ \mathrm{ml}$ solution of the endophytic fungi EFTL-10 and EFTL-13, no considerable development of anthracnose-style lesions was found in the experimental units, nor in the replicas, during the observation period $(72 \mathrm{~h})$. In the control set only inoculated with C. acutatum C-100, 35.63\% coverage of lesions was observed, yielding a lesion degree of 4 , in each of the experimental units (Table 4).

The flowers that were co-inoculated with the endophytic spore solutions before the application of the $10^{3} \mathrm{spore} / \mathrm{ml}$ phytopathogen solution (EFTL-10 + C-100; EFTL-13 + C100 ), exhibited low percentages of lesions: 0.29 and $1.85 \%$, respectively, yielding a lesion degree of 1 (Table 4). This data was analyzed using an ANOVA and Tukey test aposteriori, which demonstrated significant differences between treatments (Figure 4). Specifically, C-100 vs. EFTL-10 $(P<0.0001)$ and C100 vs. EFTL-13 $(P<0.0001)$ and without significant difference between the two treatments $(P=0.8153)$ (Figure 4). That is, the phytopathogenic fungus was inhibited by the endophytic on the flower petals; with EFTL-10 being more effective than EFTL-13 (Figure 5).

The presence of necrotic areas on Tahiti lime flower petals is common in crops of these plants, as was observed during sample collection. In the current study, a high percentage of flowers developed necrotic stains within $72 \mathrm{~h}$ in vivo after inoculation with the phytopathogenic C. acutatum C-100 spores and distilled water, with a high severity index (80\%) as shown in Table 4. The same index for plants inoculated with the endophytic spore solutions (EFTL-10 and EFTL-13) before inoculation with the phytopathogen was 1.9 and $12.40 \%$, respectively. The control exerted by the endophytic fungi over the development of necrotic areas on flower petals can thus be readily observed (Figure 5).

\section{Molecular Identification of Antagonistic Endophytic Fungi}

The molecular tests applied to the morphospecies EFTL-10 and EFTL-13 resulted in consensus sequences, which were

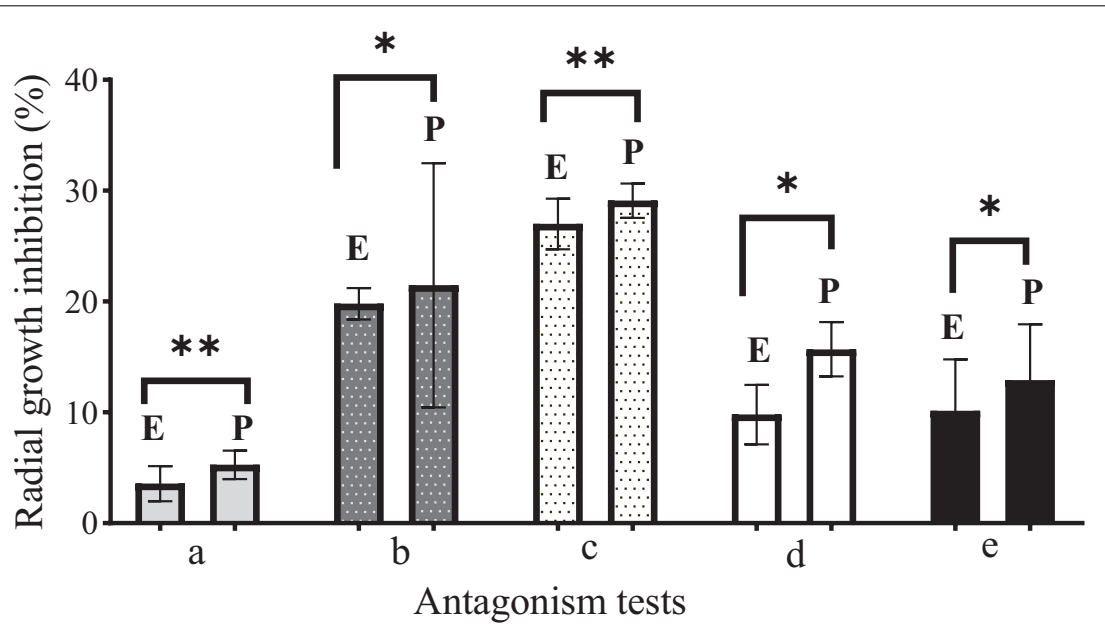

FIGURE 2 | Comparison of antagonism tests during 7 days of growth. E: Endophyte. (a) EFTL-03; (b) EFTL-04; (c) EFTL-10; (d) EFTL-12; (e) EFTL-13; P: Phytopathogen (Colletotrichum acutatun $\mathrm{C}-10)$. All dual trials are significantly different (*denotes $P<0.05)$ based on Bonferroni's range test. *denotes significant differences; ** denotes highly significant differences. 


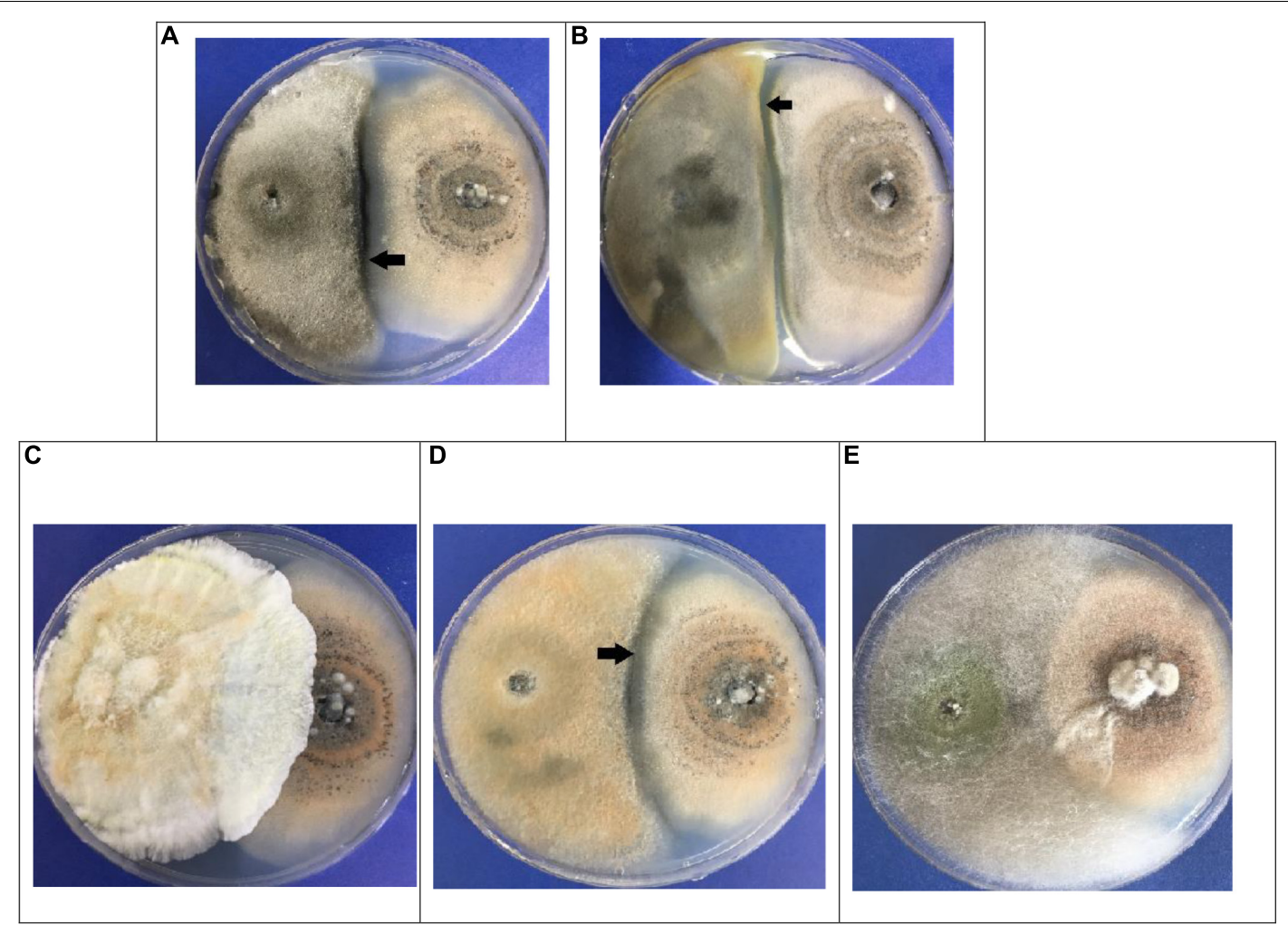

FIGURE 3 | Dual in vitro tests for endophytic fungi (left) vs. Colletotrichum acutatum C-100 (right). (A) EFTL-03/C-100; (B) EFTL-04 / C-100; (C) EFTL-10/C-100; (D) EFTL-12 / C-100; (E) EFTL-13/C-100. The black arrows indicate the zone of limiting interaction between the two fungi (>2 mm).

compared to the GenBank database, resulting in a finding of two possible species. The phylogenetic trees for the two species (Figures 6, 7), illustrate the relationships between the resulting sequences and those listed in GenBank. The endophytic fungus EFTL-10 was confirmed to be the species Xylaria adscendens, with a 99\% match to the strain KP133293.1; and the consensus tree confirmed the genus and specie, Trichoderma atroviride for EFTL-13. The distance matrix confirmed this result, showing that the lowest distance iswith Trichoderma atroviride, with a distance of 0.0020 . Both species are taxonomically within the phylum Ascomycota, and the families Xylariaceae and Hypocreaceae, respectively.

TABLE 4 | Percentages of floral lesions and percentage severity index (PSI).

\begin{tabular}{lccc}
\hline Indicators & \multicolumn{3}{c}{ Treatments } \\
\cline { 2 - 4 } & C-100 & EFTL-10 + C-100 & EFTL-13 + C-100 \\
\hline \% Lesion R1 & $37.36 \pm 12.3$ & $0.28 \pm 0.3$ & $1.96 \pm 1.0$ \\
\% Lesion R2 & $34.38 \pm 12.1$ & $0.30 \pm 0.5$ & $2.88 \pm 2.5$ \\
\% Lesion R3 & $35.16 \pm 14.3$ & $0.28 \pm 0.4$ & $0.72 \pm 1.0$ \\
Average (\%) & $35.63 \pm 1.5$ & $0.29 \pm 0.1$ & $1.85 \pm 1.1$ \\
Degreeofeffect & 4 & 1 & 1 \\
PSI (\%) & 80.00 & 1.90 & 12.40 \\
\hline
\end{tabular}

Means of percentage of flower lesions $\pm S D$.

\section{DISCUSSION}

\section{Characterization and Diversity of Endophytic Fungi From Tahiti Lime}

The endophytic fungal community associated with tissues from Tahiti lime branches, leaves, and fruit in the current study was mainly composed of fungi belonging to the phylum Ascomycota, and represented by 15 morphospecies. Although studies of diversity in citrus are very rare in the literature, in the present case, the diversity of taxa found was similar to other findings. For example, in terms of endophyte species richness, our results were similar to those of Juybari et al. (2019), who found 30 fungal taxa in leaf, bark, and xylem samples of Citrus sinensis in Iran. Likewise, Douanla-Meli et al. (2013) recorded 20 morphospecies in 482 isolates from Citrus limon. In the review "Endophytic fungi reported from Citrus species" (Nicoletti, 2019), it can be seen that the endophytic fungi genera found in various citrus species coincide with those preliminarily reported in the present study; for example, Alternaria sp., Nigrospora sp., Fusarium sp., Xylaria sp., Colletotrichum sp, Diaporthe sp., and Chaetomium sp., among other endophytes.

For the frequency of isolates from plant tissues, the greatest number were found in leaf fragments $(41.3 \%)$, closely followed by branches, but much fewer in fruit. This finding is also very similar to the Juybari et al. (2019) study, in which $46.2 \%$ of isolates originated from leaves, $34.8 \%$ from bark, and 19\% from 


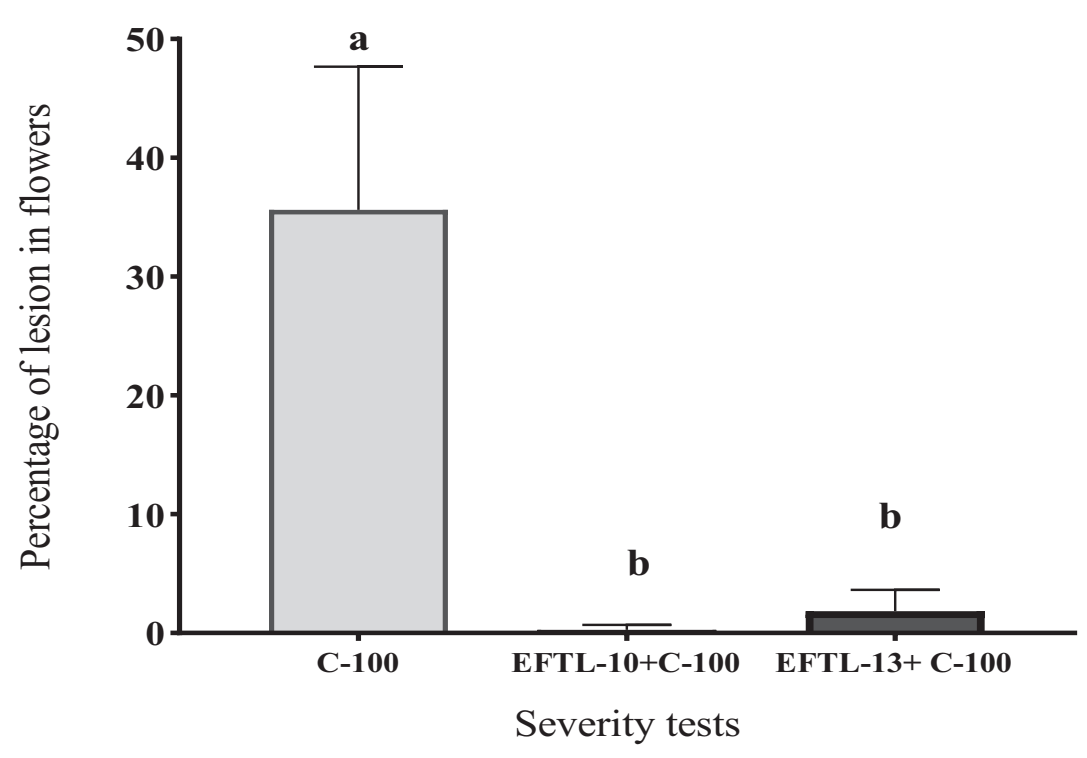

FIGURE 4 | Percentage of lesions in Tahiti lime flowers. Flowers inoculated with $20 \mu \mathrm{L}$ of spore solution to induce anthracnose: C-100 (flowers inoculated with C.acutatum- control lesions); EFTL-10 + C-100 (flowers inoculated with endophytic spore solution EFTL-10 + spores of C. acutatum at 24 h); EFTL-13 + C-100 (flowers inoculated with EFTL-13 endophyte spore solution $+C$. acutatum spores at $24 \mathrm{~h}$. Bars with different letters show significant differences ( $p<0.05)$.

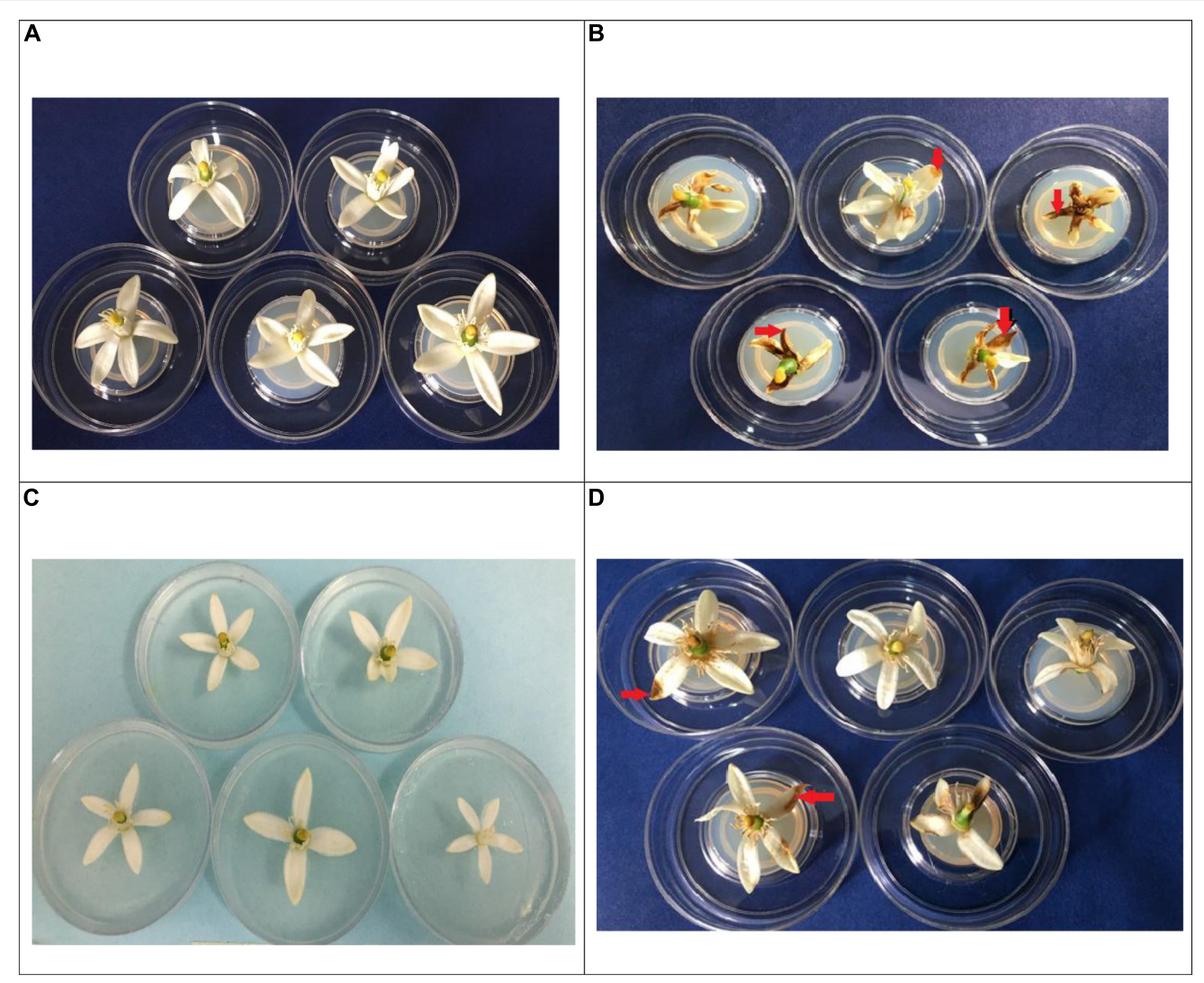

FIGURE 5 | Incidence of necrosis (red arrows), in Tahiti lime flowers. In vivo treatments: (A): flowers inoculated with distilled water control; (B): flowers inoculated with $20 \mu \mathrm{L}$ spore solution of C. acutatum C-100; (C): EFTL-10 + C-100 (flowers inoculated with $20 \mu \mathrm{L}$ of EFTL-10 endophyte spore solution + C-100 spore solution at 24 h; (D): EFTL-13 (flowers inoculated with $20 \mu \mathrm{L}$ EFTL-13 endophyte spore solution + C-100 spore solution at 24 h). 


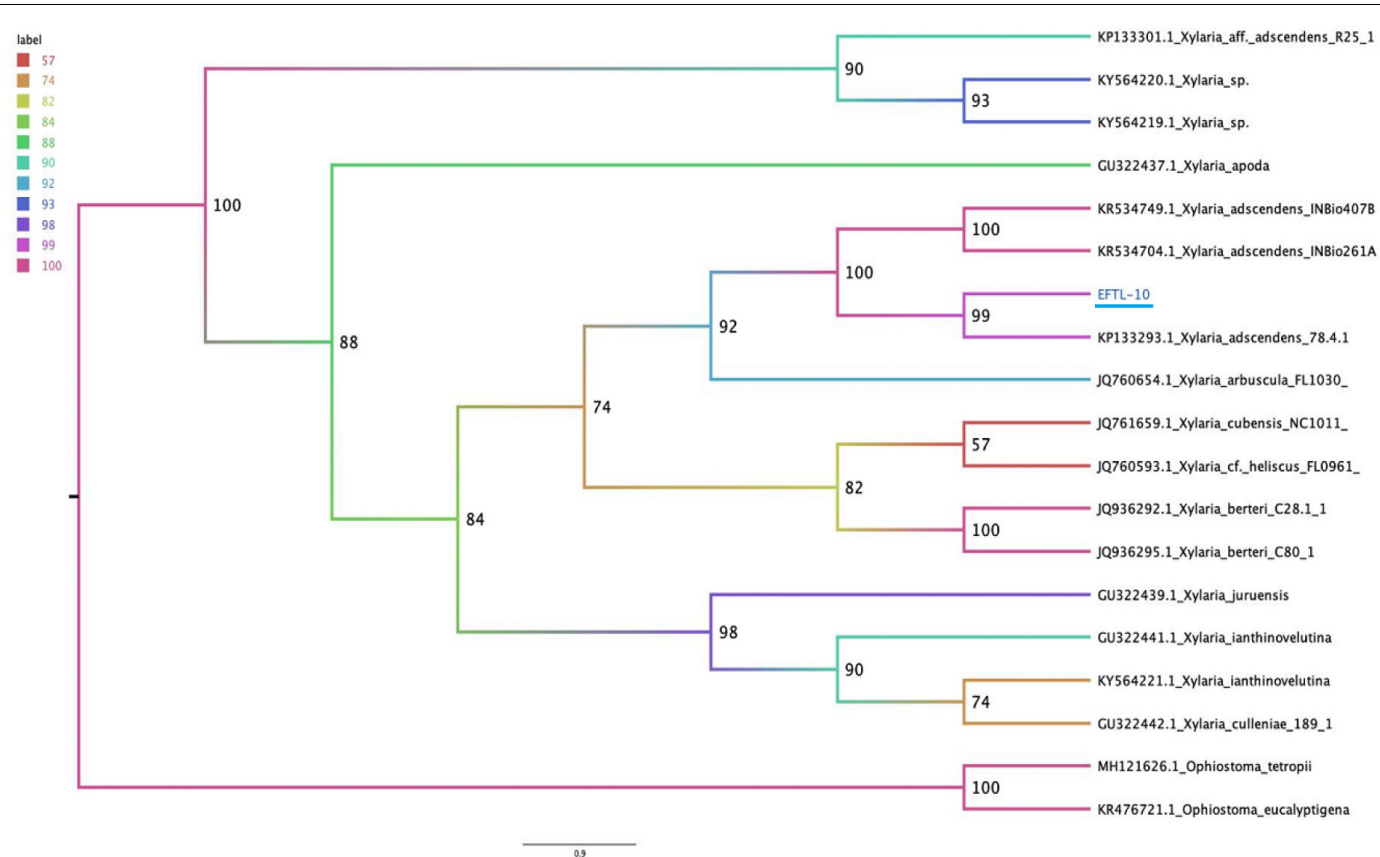

FIGURE 6 | Phylogenetic tree (Maximum likelihood) of the ITS ribosomal intergenic region of endophytic fungus EFTL-10, performed using IQtree software. We used the TIM2e+I+G4 model, Ultrafast Bootstrap (Hoang et al., 2018) with 1,000 replicates.

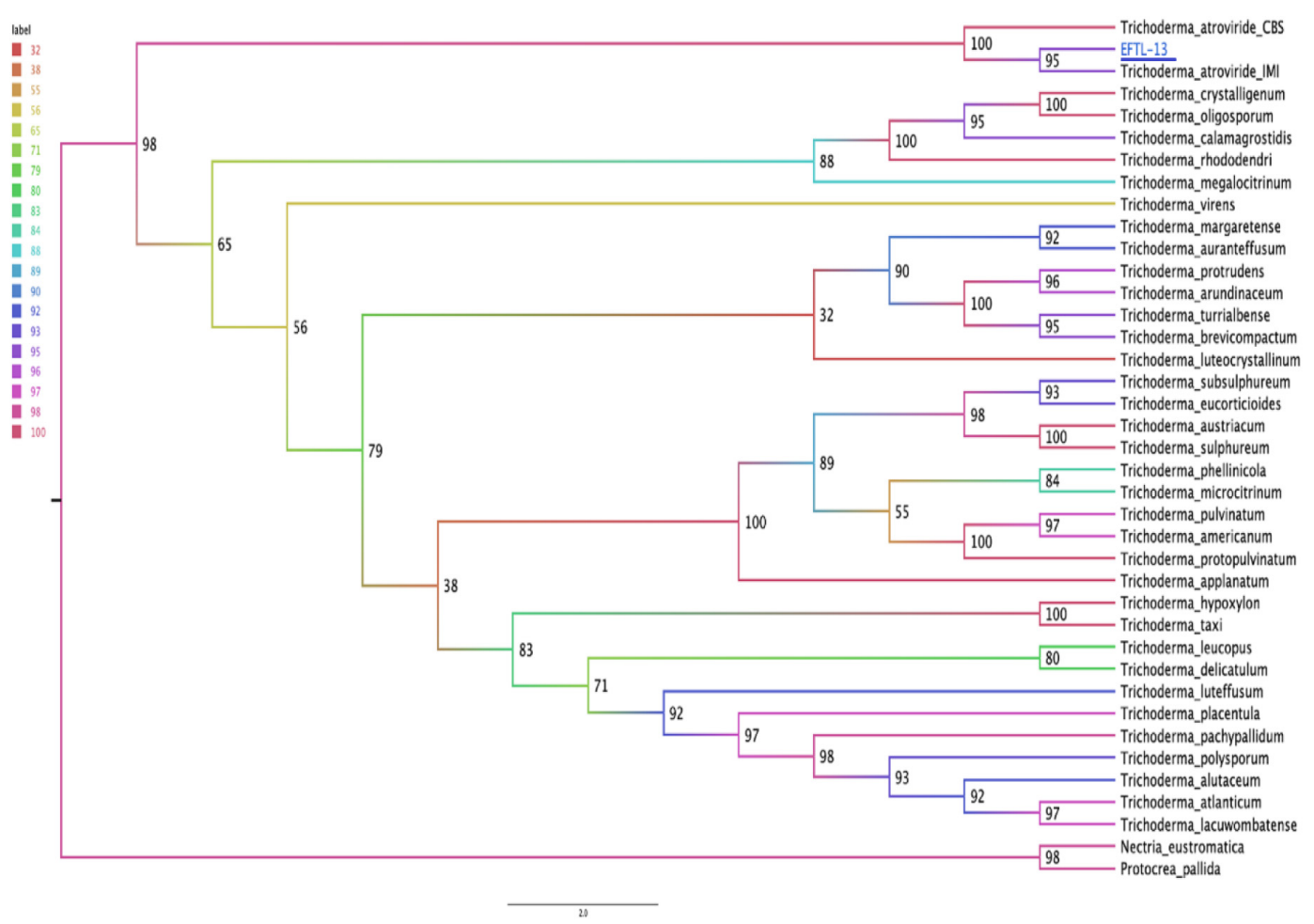

FIGURE 7 | Phylogenetic tree (Maximum likelihood) for the endophytic fungus EFTL-13. Based on two concatenated markers: the ITS ribosomal intergenic region and the TEF coding gene of the microorganism. We used the TIM2e + I + G4 model, Ultrafast Bootstrap (Hoang et al., 2018) with 1,000 replicates. The consensus tree confirmed the genus and specie, Trichoderma atroviride. 
xylem. Although the selectivity of endophytic fungal species in colonizing different plant tissues remains under debate due to the many influencing factors in play (Mane et al., 2018), it should be noted that the presence of endophytic fungal species is ubiquitous in plant tissues, being differentiated in their frequency and diversity, and possibly based upon the symbiotic capacity that they acquire with the host plant (Selim, 2012; Fesel and Zuccaro, 2016).

The Shannon-Wiener diversity indices reported in the present study for Tahiti limes, specifically those for branches (2.56) and leaves (2.52), are similar to those found by Sadeghi et al. (2019). Those authors evaluated the spatiotemporal distribution and diversity of endophytic fungi in Citrus reticulata, and found the similar indices for leaves and stems, with values of 2.55 and 2.61, respectively. The Simpson indices and evenness reported by those authors were also very similar to those in the present study. However, the difference between the richness of 15 morphospecies isolated in the present study compared with the 702 endophytes isolated by Sadeghi et al. (2019), suggests that in our case, the richness may have been limited by the breadth of sampling locations chosen, as well as the agricultural species selected, and the difficulty of isolating them from vegetal tissues (Ikram et al., 2019; Fadiji and Babalola, 2020).

\section{In vitro Antagonism Tests: Endophytic Fungi vs. Colletotrichum acutatum C-100}

In recent years, a large number of studies have reported the antagonistic effect of endophytic fungi upon phytopathogenic ones (De Silva et al., 2019; da Costa Silveira et al., 2020; Rojas et al., 2020). This effect is generally due to the production of secondary metabolites with bioactivity against these pathogens (Huang et al., 2015; Serrano et al., 2017; Latz et al., 2019). C. acutatum is one of the species of phytopathogenic fungi identified as a causal agent of anthracnose in citrus hosts (Damm et al., 2012; Barquero et al., 2013; Ben Hadj Daoud et al., 2019). Nevertheless, other species also exist, such as Colletotrichum gloeosporioides, with very similar pathogenic tendencies (Ben Hadj Daoud et al., 2019). In our study, the in vitro interactions of endophytic fungi against the phytopathogenic C. acutatum allowed us to determine that the endophytic fungi produce some substance or physiological phenomena that impedes the normal growth of the phytopathogen (Figure 2). In 3 of the 5 antagonism cases, the endophyte and the phytopathogen maintained a mutual separation in the center of the Petri dish, thus indicating that although these endophyte strains have an effect, the phytopathogen nevertheless resists them. However, in two cases, the superior growth of the endophytes indicates their greater potential as antagonists, perhaps due to the greater production of inhibitory substances.

When opposing other fungi, endophytic fungi tend to generate various effects against the antagonist (Latz et al., 2018), among these, mycoparasitism (Cao et al., 2009; Latz et al., 2018; Rajani et al., 2020), in which they directly affect the pathogen by hyphal coiling or penetration; and indirect, with only physical contact. They may also exhibit antibiosis (Wei et al., 2019), where the pathogen is inhibited by metabolites produced by the endophyte (Mousa and Raizada, 2013), and competition, where fungi compete for food, with the endophyte using the resource better (Serrano et al., 2017). Although these specific phenomena were not microscopically evaluated in the present work, the effect of endophytic fungi was evidenced in vitro against Colletotrichum acutatum as a phytopathogen (Figure 2).

The in vitro inhibitory effect of endophytic fungi against phytopathogenic species of anthracnose-causing Colletotrichum has been reported in various studies of Colletotrichum sp. For example, various endophytic fungi have been trialed against C. gloeosporioides in Amazonian plants such as guarana and açai palm, with results exhibiting inhibition by mycoparasitism and antibiosis against the pathogen (Bonatelli et al., 2016; Peters et al., 2020). Another study evaluated the effect of metabolites of the endophytic fungi Phoma herbarum, by isolating an alcoholic compound which demonstrated effective antagonism against C. gloeosporioides that cause anthracnose in Curcuma longa (Gupta et al., 2016). We were unable to find other works concerning the antagonism of endophytic fungi against Colletotrichum acutatum in citrus. However, in other species such as Olea europaea, endophytic fungi were isolated with inhibitory action against the growth of $C$. acutatum when cultivated together (Landum et al., 2016), thus confirming that this fungus can be controlled by mechanisms and active compounds of endophytic fungi.

\section{In vivo Tests: Inhibition of Severity in C. acutatum C-100}

Colletotrichum sp. infection in citrus tissues and organs usually occurs by mechanisms that depend on the tendencies of the phytopathogen (De Silva et al., 2017; Ben Hadj Daoud et al., 2019). This can occur biotrophically, where the pathogen remains within plant tissues and absorbs plant metabolites (Vargas et al., 2012) or necrotrophically, where it actively infects and colonizes plant cells, leading to cell death and being observable as dark spots or necrosis (Peres et al., 2008; Aiello et al., 2015). The tests carried out in this work demonstrated the considerable necrotrophic effect of C. acutatum (C-100) on Tahiti lime flower petals at $72 \mathrm{~h}$ after inoculation with spore solution. The percentage of lesion coverage decreased when the petals were previously inoculated with a spore solution of the 2 selected endophytic morphospecies (EFTL-10 and EFTL-13); that is, the C. acutatum C-100 strain exhibited sensitivity to the presence of endophytic fungal spores, reducing its infection capacity and severity to produce necrosis in leaves.

The inhibitory properties of the two endophytic species tested (EFTL-10 and EFTL-13) may be related to one of the mechanisms described above: antibiosis, competition, or mycoparasitism. Further studies to evaluate virulence and metabolite products of fermented liquids are key in order to put forth these endophytic fungal strains as promising candidates for the control of anthracnose. This is especially so, given that the traditional manner of control for these phytopathogens involves fungicides for agriculture in general (Chen et al., 2016; Ishii et al., 2016), and in particular for citrus crops (Peres et al., 2004), a situation which is leading to resistance in Colletotrichum species, as 
reported by Forcelini and Peres (2018) for C. acutatum species in strawberry crops. The alterative to this conventional practice is to bring sustainable agriculture technology to citrus cultivation using biological controls, including fungal microorganisms with bioactive potential against diseases. Regarding this, it is important to consider that the application of these products derived from endophytic fungi with inhibitory capacity in phytopathogenic fungi should be applied in field trials (in the same Tahiti lime or greenhouse crops), as has been done in some studies with cucumber pathogenic fungi, where 3 isolates of endophytic fungi successfully suppressed the severity of wilt when co-inoculated with the pathogen Fusarium oxysporum, in greenhouse studies (Abro et al., 2019).

\section{Molecular Identification of the Endophytic Strains EFTL-10 and EFTL-13}

The fungi EFTL-10 and EFTL-13 identified in this work, according to the GenBank search and support for phylogenetic relationships, show similarity with the species Xylaria adscendens and Trichoderma atroviride. These species of the Phylum ascomycota exhibit both free and endophyte lifestyles (Soto Medina and Bolaños Rojas, 2013; Naranjo-Ortiz and Gabaldón, 2019). Some xylaria species have been recorded as endophytes with potential for biological control of phytopathogens (Villavicencio-Vásquez et al., 2018), including in citrus plants; for example, Xylaria cubensis was isolated from healthy leaves, bark, and xylem of Citrus sinensis in different seasons and age classes in Iran (Juybari et al., 2019), and Xylaria sp. in Citrus limon (Douanla-Meli et al., 2013). Few studies were found for citrus fruits regarding the evaluation of antagonism of Xylaria species against Colletotrichum sp., except works where diversity is reported in several species (Nicoletti, 2019). However, a study similar to our current paper evaluated the inhibitory action of isolated endophytic species of Olea europaea L. on the growth of Colletotrichum acutatum, among which a morphotype of the Xylariaceae family was found, but could not be positively identified for species, that caused inhibition against the phytopathogen (Landum et al., 2016). This indicates the potential that Xylaria adscendens may have as a controller of C. acutatum in Tahiti lime.

With respect to Trichoderma sp., this is a very diverse genus, frequently associated with the roots of plants, which can promote biological control of phytopathogenic fungal species (Mukherjee et al., 2013; Rajani et al., 2020). Regarding biological control, a

\section{REFERENCES}

Abo, F. A. (2019). Endophytic fungi for sustainable agriculture. Microbial Biosystems 4, 31-44. doi: 10.21608/mb.2019.38886

Abro, M. A., Sun, X., Li, X., Jatoi, G. H., and Guo, L. D. (2019). Biocontrol potential of fungal endophytes against Fusarium oxysporum f. Sp. cucumerinum causing wilt in cucumber. Plant Pathol. J. 35, 598-608. doi: 10.5423/PPJ.OA.05.2019. 0129

Aiello, D., Carrieri, R., Guarnaccia, V., Vitale, A., Lahoz, E., and Polizzi, G. (2015). Characterization and pathogenicity of colletotrichum gloeosporioides and $\mathrm{c}$. karstii causing preharvest disease on Citrus sinensis in Italy. J. Phytopathol. 163, 168-177. doi: 10.1111/jph.12299 publication was found that reports results for the same species of $T$. atroviride considered in our study, in which the fungi was also evaluated as an antagonist against the phytopathogen Fusarium solani, finding that it is an efficient controller of the phytopathogen and significantly reducing the severity of the disease, due to the production of active compounds (Toghueo et al., 2016). Therefore, it is noteworthy that the ability to produce various metabolites and adapt to various experimental conditions, affords the fungi Xylaria adscendens and Trichoderma atroviride the possibility of being used in the biotechnology industry. As always, additional support through complementary field and laboratory research will be required to further expand the available science, and make possible their use as biological control agents against Colletotrichum acutatum in Tahiti lime.

\section{DATA AVAILABILITY STATEMENT}

The raw data supporting the conclusions of this article will be made available by the authors, without undue reservation.

\section{AUTHOR CONTRIBUTIONS}

JM-G participated in the field, laboratory, and manuscript writing activities. BG-S participated in the laboratory work and consultancy in the drafting of the document. JA participated in the review and consultancy. All authors contributed to the article and approved the submitted version.

\section{FUNDING}

This work was supported by the Universidad de SantanderColombia.

\section{ACKNOWLEDGMENTS}

We thank the University of Santander (Faculty of Exact, Natural and Agricultural Sciences) for the financial support of this work, Adriana Sandoval for her help in laboratory activities, the National Center for Genomic Sequencing-UDEA-MedellínColombia for his collaboration in molecular identification.

Arora, N. K. (2018). Agricultural sustainability and food security. Environ. Sustainabil. 1, 217-219. doi: 10.1007/s42398-018-0 0032-2

Barnett, H. L., and Hunter, B. B. (1998). Illustrated Genera of Imperfect Fungi. Minnesota, MN: The American Phytopathological Society.

Barquero, M., Perez, N., and Arauz, L. (2013). Presencia de Colletotrichum acutatum y Colletotrichum gleosporoides en helecho hoja de cuero, limón criollo, papaya, carambola y mango en costa rica Y Florida (Estados Unidos). Agronomía Costarricense 37, 23-38.

Bazioli, J. M., Costa, J. H., Akiyama, D. Y., Pontes, D. M., Kupper, K. C., and Augusto, F. (2019). Biological control of citrus postharvest phytopathogens. Toxins 11:460. doi: 10.3390/toxins 11080460 
Ben Hadj, Daoud, H., Baraldi, E., Iotti, M., Leonardi, P., and Boughalleb-M'Hamdi, N. (2019). Characterization and pathogenicity of Colletotrichum spp. causing citrus anthracnose in Tunisia. Phytopathol. Med. 58, 175-185.

Bonatelli, M. L., Tsui, S., Marcon, J., Batista, B. D., Kitajima, E. W., Pereira, J. O., et al. (2016). Antagonistic activity of fungi from anthracnose lesions on Paulliniacupana against Colletotrichum sp. J. Plant Pathol. 98, 197-205. doi: 10.4454/JPP.V98I2.029

Cannon, P. F., Damm, U., Johnston, P. R., and Weir, B. S. (2012). Colletotrichum - current status and future directions. Stud. Mycol. 73, 181-213. doi: 10.3114/ sim0014

Cao, R., Liu, X., Gao, K., Mendgen, K., Kang, Z., Gao, J., et al. (2009). Mycoparasitism of endophytic fungi isolated from reed on soilborne phytopathogenic fungi and production of cell wall-degrading enzymes in vitro. Curr. Microbiol. 59, 584-592. doi: 10.1007/s00284-009-9477-9

Caruso, G., Golubkina, N., Tallarita, A., Abdelhamid, M. T., and Sekara, A. (2020). Biodiversity, ecology, and secondary metabolites production of endophytic fungi associated with amaryllidaceae crops. Agriculture 10:533. doi: 10.3390/ agriculture 10110533

Chao, A., Chazdon, R. L., and Shen, T. J. (2005). A new statistical approach for assessing similarity of species composition with incidence and abundance data. Ecol. Lett. 8, 148-159. doi: 10.1111/j.1461-0248.2004.00707.x

Chen, S. N., Luo, C. X., Hu, M. J., and Schnabel, G. (2016). Sensitivity of Colletotrichum species, including C. Fioriniae and C. Nymphaeae, from peach to demethylation inhibitor fungicides. Plant Dis. 100, 2434-2441. doi: 10.1094/ PDIS-04-16-0574-RE

Colwell, R. K. (2004). ESTIMATES: Statistical Estimation of Species Richness and Shared Species from Samples. Version 9.1. Available online at: http://viceroy.eeb. uconn.edu/estimates

da Costa, Silveira, A. A., Araújo, L. G., de Fillipi, M. C. C., and Sibov, S. T. (2020). Isolation. identification and characterization of endophytic fungi of Bambusa oldhamii Munro applied as antagonists to Pyricularia oryzae. Revista Ceres 67, 296-305. doi: 10.1590/0034-737X202067040007

Damm, U., Cannon, P. F., Woudenberg, J. H. C., and Crous, P. W. (2012). The Colletotrichum acutatum species complex. Stud. Mycol. 73, 37-113. doi: 10. 3114/sim0010

De Silva, D. D., Crous, P. W., Ades, P. K., Hyde, K. D., and Taylor, P. W. J. (2017). Life styles of Colletotrichum species and implications for plant biosecurity. Fungal Biol. Rev. 31, 155-168. doi: 10.1016/j.fbr.2017.05.001

De Silva, N. I., Brooks, S., Lumyong, S., and Hyde, K. D. (2019). Use of endophytes as biocontrol agents. Fungal Biol. Rev. 38, 133-148. doi: 10.1016/j.fbr.2018.10. 001

Donkersley, P., Silva, F. W. S., Carvalho, C. M., Al-Sadi, A. M., and Elliot, S. L. (2018). Biological. environmental and socioeconomic threats to citrus lime production. J. Plant Dis. Prot. 125, 339-356. doi: 10.1007/s41348-018-0160-x

Douanla-Meli, C., Langer, E., and Talontsi, M. F. (2013). Fungal endophyte diversity and community patterns in healthy and yellowing leaves of Citrus limon. Fungal Ecol. 6, 212-222. doi: 10.1016/j.funeco.2013.01.004

Droby, S., Wisniewski, M., Macarisin, D., and Wilson, C. (2009). Twenty years of postharvest biocontrol research: ¿ Is it time for a new paradigm? Postharvest Biol. Technol. 52, 137-145. doi: 10.1016/j.postharvbio.2008.11.009

Estrada, S. G., and Ramírez, G. M. (2019). Micología General. Manizales: Centro Editorial Universidad Católica de Manizales.

Evans, E. A., Ballen, F. H., and Crane, J. H. (2014). Economic potential of producing tahiti limes in Southern Florida in the presence of citrus canker and citrus greening. Hort Technol. 24, 99-106. doi: 10.21273/horttech.24.1.99

Fadiji, A. E., and Babalola, O. O. (2020). Exploring the potentialities of beneficial endophytes for improved plant growth. Saudi J. Biol. Sci. 27, 3622-3633. doi: 10.1016/j.sjbs.2020.08.002

Fesel, P. H., and Zuccaro, A. (2016). Dissecting endophytic lifestyle along the parasitism/mutualism continuum in Arabidopsis. Curr. Opin. Microbiol. 32, 103-112. doi: 10.1016/j.mib.2016.05.008

Forcelini, B. B., and Peres, N. A. (2018). Widespread resistance to QoI fungicides of Colletotrichum acutatum from strawberry nurseries and production fields. Plant Health Prog. 19, 338-341. doi: 10.1094/PHP-08-18-0050-RS

Frare, G. F., Couto, H. T. Z., Ciampi-Guillardi, M., and Amorim, L. (2016). The causal agent of citrus postbloom fruit drop. Colletotrichum acutatum. can survive on weeds. Australasian Plant Pathol. 45, 339-346. doi: 10.1007/s13313016-0419-2
Goulin, E. H., dos Santos, P. J. C., Dalio, R. D., and Machado, M. A. (2019). In vitro symptom induction of Colletotrichum abscissum infection in detached sweet orange flowers. J. Plant Pathol. 101, 695-699. doi: 10.1007/s42161-018-00220-3

Gupta, S., Kaul, S., Singh, B., Vishwakarma, R. A., and Dhar, M. K. (2016). Production of gentisyl alcohol from phoma herbarum endophytic in curcuma longa l. and its antagonistic activity towards leaf spot pathogen Colletotrichum gloeosporioides. Appl. Biochem. Biotechnol. 180, 1093-1109. doi: 10.1007/ s12010-016-2154-0

Hoang, D. T., Vinh, L. S., Flouri, T., Stamatakis, A., Von Haeseler, A., and Minh, B. Q. (2018). MPBoot: fast phylogenetic maximum parsimony tree inference and bootstrap approximation. BMC Evol. Biol. 18:11. doi: 10.1186/s12862-0181131-3

Huang, Q., An, H., Song, H., Mao, H., Shen, W., and Dong, J. (2015). Diversity and biotransformative potential of endophytic fungi associated with the medicinal plant Kadsura angustifolia. Res. Microbiol. 166, 45-55. doi: 10.1016/j.resmic. 2014.12.004

Ikram, M., Ali, N., Jan, G., Jan, F. G., and Khan, N. (2019). Endophytic fungal diversity and their interaction with plants for agriculture sustainability under stressful condition. Recent Patents Food Nutrit. Agricul. 11, 115-123. doi: 10. 2174/2212798410666190612130139

Ishii, H., Zhen, F., Hu, M., Li, X., and Schnabel, G. (2016). Efficacy of SDHI fungicides, including benzovindiflupyr, against Colletotrichum species. Pest. Manag. Sci. 72, 1844-1853. doi: 10.1002/ps.4216

Jin, H., Yan, Z., Liu, Q., Yang, X., Chen, J., and Qin, B. (2013). Diversity and dynamics of fungal endophytes in leaves. stems and roots of Stellera chamaejasme L. in northwestern China. Antonie van Leeuwenhoek 104, 949963. doi: $10.1007 /$ s10482-013-0014-2

Juybari, H. Z., Tajick Ghanbary, M. A., Rahimian, H., Karimi, K., and Arzanlou, M. (2019). Seasonal, tissue and age influences on frequency and biodiversity of endophytic fungi of Citrus sinensis in Iran. Forest Pathol. 49, 1-11. doi: 10.1111/efp.12559

Kjer, J., Debbab, A., Aly, A., and Proksch, P. (2010). Methods for isolation of marine-derived endophytic fungi and their bioactive secondary products. Nat. Protoc. 5, 479-490. doi: 10.1038/nprot.2009.233

Kusari, P., Kusari, S., Spiteller, M., and Kayser, O. (2013). Endophytic fungi harbored in Cannabis sativa L.: diversity and potential as biocontrol agents against host plant-specific phytopathogens. Fungal Divers. 60, 137-151. doi: 10.1007/s13225-012-0216-3

Lakshmi, B., Reddy, P., and Prasad, R. (2011). Cross-infection potential of Colletotrichum gloeosporioides penz. isolates causing anthracnose in subtropical fruit crops. Trop. Agricul. Res. 22:183. doi: 10.4038/tar.v22i2.2827

Landum, M. C., Félix, M., do, R., Alho, J., Garcia, R., Cabrita, M. J., et al. (2016). Antagonistic activity of fungi of Olea europaea L. against Colletotrichum acutatum. Microbiol. Res. 183, 100-108. doi: 10.1016/j.micres.2015.12.001

Latz, M. A. C., Jensen, B., Collinge, D. B., and Jørgen Lyngs Jørgensen, H. (2019). Identification of two endophytic fungi that control Septoria tritici blotch in the field, using a structured screening approach. Biol. Control. 141:104128. doi: 10.1016/j.biocontrol.2019.104128

Latz, M. A. C., Jensen, B., Collinge, D. B., and Jørgensen, H. (2018). Endophytic fungi as biocontrol agents: elucidating mechanisms in disease suppression. Plant Ecol. Diversity 11, 555-567. doi: 10.1080/17550874.2018.1534146

Lima, W. G., Spósito, M. B., Amorim, L., Gonçalves, F. P., and de Filho, P. A. M. (2011). Colletotrichum gloeosporioides, a new causal agent of citrus post-bloom fruit drop. Eur. J. Plant Pathol. 131, 157-165. doi: 10.1007/s10658-011-9795-1

López, R. C., Gómez, C. S., De la Rosa-García, S. C., Garrido, E., Oropeza-Mariano, O., Heil, M., et al. (2017). The age of lima bean leaves influences the richness and diversity of the endophytic fungal community, but not the antagonistic effect of endophytes against Colletotrichum lindemuthianum. Fungal Ecol. 26, 1-10. doi: 10.1016/j.funeco.2016.11.004

Mane, R. S., Paarakh, P. M., and Vedamurthy, A. B. (2018). Brief review on fungal endophytes. Int. J. Secondary Metab. 5, 288-303. doi: 10.21448/ijsm.482798

Martinez, E., Hio, J., Osorio, J., and Torre, M. F. (2009). Identification of Colletotrichum species causing anthracnose on Tahiti lime. tree tomato and mango. AgronomíaColombiana 27, 211-218.

Mogollón, ÁM., López, C. N., and Orduz, J. O. (2021). Efecto de las variables meteorológicas sobre la antracnosis (Colletotrichum acutatum) de la lima ácida Tahití en el piedemonte llanero, Colombia. Rev. Acad. Colomb. Cienc. Ex. Fis. Nat. 45, 250-259. doi: 10.18257/raccefyn. 1237 
Mousa, W. K., and Raizada, M. N. (2013). The diversity of anti-microbial secondary metabolites produced by fungal endophytes: an interdisciplinary perspective. Front. Microbiol. 4:65. doi: 10.3389/fmicb.2013.00065

Mukherjee, P. K., Horwitz, B. A., Herrera, A., Schmoll, M., Charles, M., and Kenerley. (2013). Trichoderma research in the genome era. Annu. Rev. Phytopathol. 51, 105-29. doi: 10.1146/annurev-phyto-082712-102353

Naranjo-Ortiz, M. A., and Gabaldón, T. (2019). Fungal evolution: diversity, taxonomy and phylogeny of the Fungi. Biol. Rev. 94, 2101-2137. doi: 10.1111/ brv. 12550

Nicoletti, R. (2019). Endophytic fungi of citrus plants. Agriculture 9:247. doi: 10. 3390/agriculture9120247

Ortega, H. E., Torres-Mendoza, D., and Cubilla-Rios, L. (2020). Patents on endophytic fungi for agriculture and bio-and phytoremediation applications. Microorganisms 8:1237. doi: 10.3390/microorganisms 8081237

Palou, L., Smilanick, J. L., and Droby, S. (2008). Alternatives to conventional fungicides for the control of citrus postharvest green and blue moulds. Stewart Postharvest Rev. 4, 1-16. doi: 10.2212/spr.2008.2.2

Pekas, A. (2011). "Biological pest control in citrus an alternative to chemical pesticides with benefits for essential oil quality," in Proceedings of the IFEAT International Conference, (Barcelona: FC Barcelona Football club), 115-124.

Peres, N. A., MacKenzie, S. J., Peever, T. L., and Timmer, L. W. (2008). Postbloom fruit dropof citrus and Key lime anthracnose are caused by distinct populations of Colletotrichum acutatum. Phytopathology 98, 345-352.

Peres, N. A. R., Souza, N. L., Peever, T. L., and Timmer, L. W. (2004). Benomyl sensitivity of isolates of Colletotrichum acutatum and C. gloeosporioides from citrus. Plant Dis. 88, 125-130. doi: 10.1094/PDIS.2004.88.2.125

Peters, L. P., Prado, L. S., Silva, F. I. N., Souza, F. S. C., and Carvalho, C. M. (2020). Selection of endophytes as antagonists of Colletotrichum gloeosporioides in açaí palm. Biol. Control 150:104350. doi: 10.1016/j.biocontrol.2020.104350

Price, C. L., Parker, J. E., Warrilow, A. G., Kelly, D. E., and Kelly, S. L. (2015). Azole fungicides - understanding resistance mechanisms in agricultural fungal pathogens. Pest. Manag. Sci. 71, 1054-1058. doi: 10.1002/ps.4029

Rajani, P., Rajasekaran, C., Vasanthakumari, M. M., Olsson, S. B., Ravikanth, G., and Uma Shaanker, R. (2020). Inhibition of plant pathogenic fungi by endophytic Trichoderma spp. through mycoparasitism and volatile organic compounds. Microbiol. Res. 242:126595. doi: 10.1016/j.micres.2020.126595

Ramos, A. P., Talhinhas, P., Sreenivasaprasad, S., and Oliveira, H. (2016). Characterization of Colletotrichum gloeosporioides, as the main causal agent of citrus anthracnose, and C. karstii as species preferentially associated with lemon twig dieback in Portugal. Phytoparasitica 44, 549-561. doi: 10.1007/s12600016-0537-y

Rhaiem, A., and Taylor, P. W. J. (2016). Colletotrichum gloeosporioides associated with anthracnose symptoms on citrus, a new report for Tunisia. Eur. J. Plant Pathol. 146, 219-224. doi: 10.1007/s10658-016-0907-9

Rojas, E. C., Jensen, B., Jørgensen, H. J. L., Latz, M. A. C., Esteban, P., Ding, Y., et al. (2020). Selection of fungal endophytes with biocontrol potential against Fusarium head blight in wheat. Biol. Control 144:104222. doi: 10.1016/j. biocontrol.2020.104222

Sadeghi, F., Samsampour, D., Seyahooei, M. A., Bagheri, A., and Soltani, J. (2019). Diversity and spatiotemporal distribution of fungal endophytes associated with Citrus reticulata cv. Siyahoo. Curr. Microbiol. 76, 279-289. doi: 10.1007/s00284019-01632-9

Segaran, G., and Sathiavelu, M. (2019). Fungal endophytes: a potent biocontrol agent and a bioactive metabolites reservoir. Biocatalysis Agricul. Biotechnol. 21:101284. doi: 10.1016/j.bcab.2019.101284

Selim, K. (2012). Biology of endophytic Fungi. Curr. Res. Environ. Appl. Mycol. 2, 31-82. doi: 10.5943/cream/2/1/3

Serrano, R., González-Menéndez, V., Rodríguez, L., Martín, J., Tormo, J. R., and Genilloud, O. (2017). Co-culturing of fungal strains against Botrytis cinerea as a model for the induction of chemical diversity and therapeutic agents. Front. Microbiol. 8:649. doi: 10.3389/fmicb.2017.00649

Shivakumar, K., Palaiah, P., Sunnkad, G., Mallesh, S., and Pampanna, Y. (2016). Pathogenicity of different isolates of anthracnose of mango caused by Colletotrichum gloeosporioides (Penz.) Penz. and Sacc. J. Farm Sci. 28, 536-538.

Silva-Junior, G. J., Spósito, M. B., Marin, D. R., Ribeiro-Junior, P. J., and Amorim, L. (2014). Spatiotemporal characterization of citrus postbloom fruit drop in Brazil and its relationship to pathogen dispersal. Plant Pathol. 63, 519-529. doi: 10.1111/ppa.12138

Soto Medina, E., and Bolaños Rojas, A. C. (2013). Xylariaceae en un bosque de Niebla del Valle del Cauca (Colombia). Rev. Acad. Colomb. Cienc. 37, 343-351.

Tennant, P. F., Robinson, D., Fisher, L., Bennett, S.-M., Hutton, D., CoatesBeckford, P., et al. (2009). Diseases and pests of citrus (Citrus spp.). Tree Forestry Sci. Biotechnol. 3, 81-107.

Tibpromma, S., Hyde, K. D., Bhat, J. D., Mortimer, P. E., Xu, J., Promputtha, I., et al. (2018). Identification of endophytic fungi from leaves of Pandanaceae based on their morphotypes and DNA sequence data from southernThailand. MycoKeys 33, 25-67. doi: 10.3897/mycokeys.33.23670

Toghueo, R. M. K., Eke, P., Zabalgogeazcoa, Í, de Aldana, B. R. V., Nana, L. W., and Boyom, F. F. (2016). Biocontrol and growth enhancement potential of two endophytic Trichoderma spp. from Terminalia catappa against the causative agent of Common Bean Root Rot (Fusarium solani). Biol. Control 96, 8-20. doi: 10.1016/j.biocontrol.2016.01.008

Vargas, W., Sanz, J. M., Rech, G. E., Rivera, P., Benito, E., Díaz, J. M., et al. (2012). Plant defense mechanisms are activated during biotrophic and necrotrophic development of Colletotricum graminicola in Maize. Plant Physiol. 158, 13421358. doi: $10.1104 /$ pp.111.190397

Villavicencio-Vásquez, M., Espinoza-Lozano, R. F., Pérez-Martínez, S., Sosa, and del Castillo, D. (2018). Foliar endophyte fungi as candidate for biocontrol against Moniliophthora spp. of Theobroma cacao (Malvaceae) in Ecuador. Acta biol. Colomb. 23, 235-241. doi: 10.15446/abc.v23n3.69455

Wang, W., de Silva, D. D., Moslemi, A., Edwards, J., Ades, P. K., Crous, P. W., et al. (2021). Colletotrichum species causing anthracnose of citrus in australia. J. Fungi 7, 1-24. doi: 10.3390/jof7010047

Wang, Z., Sui, Y., Li, J., Tian, X., and Wang, Q. (2020). Biological control of postharvest fungal decays in citrus: a review. Crit. Rev. Food Sci. Nutrit. doi: 10.1080/10408398.2020.1829542 Online ahead of print.

Wang, Z., Jiang, M., Chen, K., Wang, K., Du, M., Zalán, Z., et al. (2018). Biocontrol of Penicillium digitatum on postharvest citrus fruits by Pseudomonas fluorescens. J. Food Qual. 2018, 1-10. doi: 10.1155/2018/2910481

Wei, F., Zhang, Y., Shi, Y., Feng, H., Zhao, L., Feng, Z., et al. (2019). Evaluation of the biocontrol potential of endophytic fungus Fusarium solani CEF559 against Verticillium dahliae in cotton plant. BioMed Res. Int. 2019:3187943. doi: 10.1155/2019/3187943

Yoon, M. Y., Cha, B., and Kim, J. C. (2013). Recent trends in studies on botanical fungicides in agriculture. Plant Pathol. J. 29, 1-9. doi: 10.5423/PPJ.RW.05.2012. 0072

Conflict of Interest: The authors declare that the research was conducted in the absence of any commercial or financial relationships that could be construed as a potential conflict of interest.

Copyright (๑) 2021 Muñoz-Guerrero, Guerra-Sierra and Alvarez. This is an openaccess article distributed under the terms of the Creative Commons Attribution License (CC BY). The use, distribution or reproduction in other forums is permitted, provided the original author(s) and the copyright owner(s) are credited and that the original publication in this journal is cited, in accordance with accepted academic practice. No use, distribution or reproduction is permitted which does not comply with these terms. 